\title{
IMIGRANTES TEMPORÁRIOS EM BRASÍLIA: A INSERÇÃO DOS ESTUDANTES AFRICANO-LUSÓFONOS NA SOCIEDADE BRASILEIRA*
}

\begin{abstract}
Ilana de Castro Guimarães ${ }^{* *}$
Resumo: O presente trabalho analisa a inserção dos estudantes africanos provenientes dos países lusófonos em Brasília. Foram analisadas questões referentes à elaboração das identidades nacionais dos estudantes entrevistados no Brasil, como é a relação deles entre si e como reagem ao preconceito brasileiro. Tenta-se verificar em que medida os estudantes se sentem excluídos do "nós" nacional brasileiro, examina-se a influência da posição social dos estudantes na relação com os brasileiros e procura-se averiguar a imagem da sociedade brasileira pré-concebida por muitos como harmônica, a qual é desmistificada no contato dos estudantes africanos com os brasileiros.
\end{abstract}

Palavras-chave: Identidade nacional; Preconceito; Etnicidade; Cultura; Africanos em Brasília;

\section{Introdução}

O Brasil possui um importante Acordo de Cooperação Educacional com 49 países em vias de desenvolvimento denominado "Programa de Estudantes-Convênio de Graduação", que disponibiliza vagas em universidades de todo o Brasil para que estudantes, provenientes especialmente da África e da América Latina, tenham uma formação qualificada.

Esta pesquisa investiga os estudantes dos países africanos que fazem parte da Comunidade dos Países de Língua Portuguesa (CPLP) - Angola, Cabo Verde, GuinéBissau, Moçambique e São Tomé e Príncipe - e que vêm ao Brasil estudar através do Programa de Estudantes-Convênio de Graduação (PEC-G). Em Brasília, cidade pesquisada, há sessenta estudantes, os quais estudam na Universidade de Brasília, que é a única Instituição de Ensino Superior do Distrito Federal que participa do Programa e recebe assim os estudantes.

A análise está direcionada em três vertentes: a primeira leva em consideração o aspecto nacional, o qual se preocupa em analisar como estes estudantes africanos elaboram suas identidades nacionais no Brasil, a segunda analisa o aspecto inter-nacional, que busca

\footnotetext{
* Estudante de Relações Internacionais do Centro Universitário de Brasília.
} 
saber como é relação inter-identitária dos estudantes africanos com o Brasil e também com os outros países africanos de língua portuguesa e a terceira se dedica ao aspecto xenófobo, que verifica em que medida eles se sentem excluídos do "nós" nacional brasileiro.

\section{Metodologia}

A reflexão procurou comparar as discussões sobre raça, nacionalismo e póscolonialismo aos discursos dos estudantes africanos em Brasília. Buscando analisar as interpretações dos estudantes sobre suas identidades nacionais, e seu processo de elaboração no contexto brasileiro, entrevistei cinco estudantes africanos: Leandro, de Guiné-Bissau, estudante de Sociologia, de 28 anos; Sônia, de Guiné-Bissau, estudante de Pedagogia, de 22 anos; Carlos, estudante angolano de Geologia, de 20 anos; outro rapaz de Angola de 28 anos que cursa Administração, o Antônio; e um rapaz de São Tomé e Príncipe que cursa Engenharia Mecatrônica e tem 22 anos, o Eduardo.

O universo total dos estudantes africano-lusófonos que estudam na Universidade de Brasília compreende o total de 60 alunos $^{1}$. Minha pesquisa foi muito tensa no contato com os estudantes, pois senti grande dificuldade em encontrar estudantes dispostos em expor suas trajetórias. Nesse sentido, cabe detalhar como foi a inserção e a receptividade dos estudantes abordados na pesquisa de campo.

Evans Pritchard, antropólogo que fez uma importante pesquisa no começo da década de 30 os Nuer, povo nilota do sul do Sudão, relata problemas similares em sua pesquisa de campo e sua adaptação entre os nuer:

"Seria difícil, em qualquer época, fazer pesquisas entre os Nuer, e, no entanto, no período de minha visita, eles estavam extremamente hostis, pois sua recente derrota pelas forças governamentais e as medidas tomadas para garantir sua submissão final tinha provocado profundos ressentimentos. (...) Quando eu entrava em um campo de criação de gado, fazia-o não somente na qualidade de estrangeiro, como também na qualidade de inimigo, e eles pouco esforço faziam para disfarçar a aversão à minha presença,

\footnotetext{
${ }^{1}$ Informação obtida na Universidade de Brasília e válida até o começo do ano de 2005, ocasião a qual ingressarão mais estudantes na Universidade pelo PEC-G.
} 
recusando-se a responder a minhas saudações e chegando mesmo a dar-me as costas quando me dirigia a eles." 2

Dirigindo esta observação à minha pesquisa, pude perceber que a rejeição dos estudantes africanos manifestava-se através da impossibilidade de marcação de entrevistas e não atendimento de meus telefonemas.

Os campos de pesquisa são sempre tensos, pois há a definição entre "nós" e "os outros" e uma relação entre sujeito e objeto, a qual muitas vezes incomoda tanto o pesquisador quanto o pesquisado. O grau de tensão pode aumentar ou diminuir ao longo da pesquisa e é condicionado por fatores que muitas vezes não depende da habilidade do pesquisador. A subjetividade do processo de investigação é suscetível se acontecer em qualquer pesquisa, pois quando escolhemos o objeto de estudo ainda não temos noção prática de como é o campo de investigação, ou seja, não se pode prever como vai ser a receptividade e modo de inserção naquele grupo pesquisado.

\section{Desenvolvimento da Pesquisa}

Apesar do senso comum muitas vezes considerar a África como um continente homogêneo, sem colocar foco nas diferenças lingüísticas, étnicas e culturais que distinguem seus povos de maneira análoga, a heterogeneidade das nações africanas refletiu-se na heterogeneidade dos estudantes pesquisados, os quais vêm de países distintos, e que acabam construindo visões muito particulares de mundo, do Brasil e de Brasília.

A imagem africana formada no exterior envolve argumentos pré-estabelecidos, sem verificações e averiguações, pois as pessoas acabam tendo idéias distorcidas do que é ser africano e estigmas acabam sendo criados em torno dessas imagens. Anthony Appiah, filósofo ganês que relata aspectos que envolvem identidade nacional africana e a própria construção dessa cultura, diz:

"O desaparecimento da difundida crença no negro como categoria biológica não deixaria nenhum traço diante do qual os racistas pudessem ter uma atitude. Mas não ofereceria, por si só, uma garantia de que os africanos escapassem ao estigma de séculos. (...) Sua confiante reiteração demonstraria apenas a persistência de velhos

\footnotetext{
${ }^{2}$ PRITCHARD, Evans. E. Os Nuer: Uma descrição do modo de subsistência e das instituições políticas de um povo nilota. São Paulo: Editora Perspectiva, 2002, p. 17.
} 
preconceitos em novas formas. Mas, até mesmo essa visão seria, sob certo aspecto, um avanço em relação ao racismo extrínseco, pois significaria que cada africano precisaria ser julgado por seus próprios méritos. Sem uma informação cultural, saber que alguém é de origem africana fornece pouca base para se supor grande coisa a seu respeito." 3

Assim, apesar dos africanos terem um aspecto comum, que é o modo de colonização o qual sofreram, que incluiu a divisão do continente africano entre os europeus sem os mesmos levarem em conta diferenças existentes entre as tribos, separando tribos comuns ou unindo tribos rivais, e também apresentarem consequiências e reflexos culturais dos colonizadores europeus, cabe salientar que a África é um continente extremamente heterogêneo e com enormes diferenças entre os povos.

Pôde ser percebido que no grupo entrevistado os estudantes elaboram suas identidades nacionais principalmente quando se compara o país de cada um com os outros países africanos, tendo em vista que nessas situações há a separação entre "nós" e "eles". Segundo o Carlos*, estudante angolano de 20 anos:

“(...) angolano tem nariz mais empinado do que os outros africanos, não tem como, mesmo se não for filho de diplomata. Entre os angolanos não tem diferença por ser filho de diplomata, é normal. Mas entre os africanos, é bem possível que eles vêem de maneira diferente."

Para o Carlos, há uma maneira diferente de ver as situações e se relacionar com as pessoas por ser angolano e por conviver com filhos de diplomatas angolanos, criando assim uma hierarquia dentro do grupo.

Leandro*, proveniente de Guiné-Bissau, estudante de Sociologia de 28 anos, também comprova essa hierarquização e o intuito de demonstrar união entre os estudantes de seu país de origem, Guiné-Bissau, quando ele diz: "Tem sempre um provérbio que a gente fala: "Guineense não se separa",. Deste modo, os estudantes acabam querendo mostrar aos outros grupos que são unidos e que mantém uma relação forte entre si.

\footnotetext{
${ }^{3}$ APPIAH, Kwame Anthony. Na Casa de Meu Pai: a África na Filosofia da Cultura. Rio de Janeiro: Contraponto, 1997, p. 65-67.

* Nome fictício.
} 
A identidade cultural é baseada na comparação da cultura própria com elementos da cultura de outros países, gerando uma hierarquização cultural, ou simplesmente encontrando pontos que possam unir culturas tidas como distintas.

Oracy Nogueira explica como o negro colonizado incorpora a cultura do colonizador, tida como hegemônica e superior, e em seu discurso interioriza os hábitos europeus:

“... o drama do negro que, vivendo no mundo dos brancos, é induzido, ainda que com relutância a interiorizar os valores culturais deste, inclusive em sua preferência etnocêntrica pelos característicos físicos caucasóides; do negro que, subjugado pelo branco, introjeta sua imagem e vê a si mesmo do ponto de vista dele. É o drama do negro colonizado, escravizado, destribalizado, despojado de sua cultura e imerso na cultura do branco." ${ }^{4}$

Antônio , estudante de Angola, que tem 28 anos e cursa Administração, considera a relação entre Angola e o Brasil harmônica, e relata:

"Então os nossos hábitos passaram a ser portugueses, porque eles dominavam Angola e a língua oficial é o português, e os hábitos passaram a ser portugueses, passaram a ser hábitos coloniais, tanto em comida, no jeito de falar, no jeito da gente se comunicar, e por aí vai. (...) Mas muitos portugueses ficaram em Angola, constituíram famílias, muitos são casados com angolanas, angolanos casados com portuguesas, e quer dizer, todo um fator que cria uma união social, e hoje em dia está tudo bem. Angola tem Acordos bilaterais com Portugal, há muitos angolanos que têm dupla nacionalidade, nacionalidade angolana e portuguesa, a mesma coisa com os portugueses, que têm nacionalidade portuguesa e nacionalidade angolana. Então é uma harmonia que se vive entre os dois países, tanto na parte política, quanto na social e cultural, há toda uma integração.”

O discurso anterior caracteriza o que Frantz Fanon explica como a interiorização dos valores do colonizador na construção da própria identidade nacional. E a identidade nacional desses dois estudantes angolanos está extremamente ligada ao pensamento da burguesia colonial. O autor explica: "Para assimilar a cultura do opressor e aventurar-se

\footnotetext{
${ }^{4}$ NOGUEIRA, ORACY. Tanto preto quanto branco: estudo de relaçães raciais. São Paulo: T.A. Queiroz, 1985, p. 16.

* Nome fictício.
} 
nela, o colonizado teve de fornecer garantias. Entre outras coisas, teve de fazer suas as formas de pensamento da burguesia colonial."

A elaboração das identidades nacionais está extremamente ligada ao modo como ocorreu o processo colonizador e como cada pessoa se inseriu no mesmo, o que também inclui a classe social de cada um, pois há maneiras diferentes de se perceber os fenômenos se uma pessoa está inserida na elite local ou não.

Em relação à língua portuguesa e em como o grupo entrevistado proveniente de países colonizados pelos portugueses percebem a imposição dessa língua em suas sociedades, pôde ser percebido que a língua portuguesa como fator de união entre os países é um argumento muito frágil. Ele não tem consistência na medida em que grande parcela da população de Guiné-Bissau, por exemplo, não o fala entre seus familiares e colegas. Como Leandro diz:

\begin{abstract}
"Geralmente a gente fala que (o português) nem é língua oficial. Assim, tem uns tipos de língua de colônia, de imperialista, que ficam pisando no crioulo, que é a língua nacional. (...) As aulas são em português. Mas por exemplo, os alunos conversam em crioulo. O professor falando em português e eles conversando em crioulo, entre os amigos. (...) Aí é muito difícil de se brigar. Por quê? Porque se a gente brigar e chegar na diretoria do Conselho Disciplinar você vai ter que falar português."
\end{abstract}

A língua, como argumento frágil em relação a unificação de nações, e formação de uma real unidade é explicitada no discurso de Hobsbawm:

"Na verdade, por que a língua deveria ser um critério de vínculo a grupo, com exceção talvez do caso em que a diferenciação de língua talvez coincida com alguma outra razão para marcar a pessoa como externa, pertencente a outra comunidade? Como uma instituição, o próprio casamento não pressupõe a comunidade da língua, caso contrário não haveria exogamia institucionalizada. (...) Em algumas áreas, as estatísticas lingüísticas oscilam desordenadamente de um censo para outro desde que a identificação com um idioma dependa não do conhecimento, mas de algum outro fator mutável (...) As pessoas em Maurício não escolhem arbitrariamente entre falar créole ou sua própria língua doméstica, porque usam cada uma com diferente objetivos (.....”’

\footnotetext{
${ }^{5}$ FANON, Frantz. Os Condenados da Terra. Rio de Janeiro: Civilização Brasileira, 1968, p. 32.

${ }^{6}$ HOBSBAWM, Eric J. Nações e nacionalismos desde 1780: programa, mito e realidade. Rio de Janeiro: Paz e Terra, 1990, p. 73 - 74.
} 
Os argumentos acima citados em relação ao papel frágil que a língua pode ter na formação das nações e na ligação entre Estados que falem a mesma língua vão contra ao que Gilberto Freyre diz em seu discurso: “(...) semelhanças que fazem de nós portugueses, brasileiros e luso-descendentes da África, da Ásia e das ilhas - uma unidade cultural das mais vivas e das mais cheias de possibilidades."7 Para Freyre os países colonizados pelos portugueses têm um grande laço em comum e apresentam várias semelhanças que unem todos esses países. Mas, na verdade, apesar da língua ser fator de ligação entre os povos, ela não é fator forte o suficiente para ser considerado como preponderante na relação entre países.

Antônio explica que, mesmo que Angola e Brasil falem o português, esse idioma pode ser fator de dificuldade de comunicação entre ambos os países:

“Apesar de nós falarmos a mesma língua, a questão da comunicação influencia muito. Eu lembro que quando eu cheguei, em 1996, até 1997, os brasileiros não me entendiam. Eu conversava e português, e os brasilienses não me entendiam. (...) A língua é a mesma, inclusive as conjugações verbais, mas o sotaque é um pequeno ponto que já influencia na relação."

A construção da imagem brasileira entre os estudantes pesquisados é baseada em novelas e no que a mídia em seus países mostra sobre o Brasil. Mas toda essa imagem brasileira de povo unido, pacífico e harmonicamente construído, vem de uma noção em grande parte elaborada pelas idéias de Gilberto Freyre, escritor que teve prestígio no Brasil e no exterior.

Gilberto Freyre argumenta:

"Híbrida desde o início, a sociedade brasileira é de todas da América a que se constituiu mais harmoniosamente quanto às relações de raça: dentro de um ambiente de quase reciprocidade cultural que resultou no máximo de aproveitamento dos valores e experiências dos povos atrasados pelo adiantado (...).",

Sandra*, estudante de Guiné-Bissau, de 22 anos e que cursa Pedagogia, tinha em mente antes de vir ao Brasil somente as características que a maioria das pessoas têm no

\footnotetext{
${ }^{7}$ FREYRE, Gilberto. O mundo que o português criou: Aspectos das relações sociais e de cultura do Brasil com Portugal e as colonias portuguesas. Rio de Janeiro: Livraria José Olympio Editora, 1940, p. 63.

${ }^{8}$ FREYRE, Gilberto. Casa Grande e Senzala. São Paulo, Global, 2003, p. 91.

* Nome fictício.
} 
exterior, as quais são construídas pela televisão, por novelas ou notícias. Segundo ela: "Eu não tinha noção nenhuma de como seria o Brasil. A única coisa é aquela fantasia de Brasil, um país tropical, lindo, tem gente bonita, as novelas, o carnaval. Inclusive a gente ouve muita coisa, quer dizer, nada a ver, de que o Brasil pára, o país inteiro pára só para assistir o carnaval durante um mês."

A construção da imagem brasileira pelos meios de comunicação também influenciou os pensamentos de Eduardo **, estudante de São Tomé e Príncipe, de 22 anos e que cursa Engenharia Mecatrônica:

"É assim, a imagem que a gente tem lá é que o Brasil é um país tranqüilo, não tem preconceito. Isso vinha na minha cabeça, só isso que pensei. Eu não tinha ouvido falar muito de Brasília, lá a gente tinha mais informações de São Paulo, Rio de Janeiro, agora Brasília muito pouco. Até nas novelas fala-se pouco de Brasília, nos noticiários.”

Antônio também diz que a imagem que tinha do Brasil era outra, totalmente diferente da que encontrou aqui. Ou seja, a sua concepção mudou ao perceber as enormes alteridades e diferenças as quais percebeu no Brasil. Segundo ele:

"É por causa da imagem que o Brasil passa para o exterior. A Globo é uma cadeia televisiva que tem poder muito grande no Brasil, e o que tinha de referência era carnaval, futebol e novelas. Então quer dizer, quem criou essa referência internacionalmente foi a Globo. Ela passa imagens de futebol, novelas, carnaval, então quer dizer, a gente vê toda uma miscigenação na mídia, na TV. Toda aquela confraternização, festas, lindas praias, e outra coisa, nas novelas a Globo não mostra as favelas. Hoje em dia eu acho que já mudou um pouco a concepção, mas nós não víamos violência em novelas."

Ao chegar em Brasília ele explica como reagiu ao verificar que as suas préconcepções eram equivocadas:

"Então quer dizer, eu chegando ao Brasil eu tive um choque, principalmente aqui em Brasília, que eu tinha noção de carnaval, futebol, essa miscigenação, e Brasília pareceu mais a Europa, eu não consegui encontrar aqui aquela referência que o país tem no exterior, toda aquela beleza cultural."

\footnotetext{
** Nome fictício.
} 
A relação dos estudantes entrevistados com os brasileiros ocorre de maneira restrita, e na verdade eles não convivem muito com os brasileiros, pois já que sentem o preconceito, a tendência deles é se afastarem dos brasileiros e se unirem mais entre eles.

Há uma grande união entre os africanos. Segundo Anthony Appiah:

“(...) Assim, embora o europeu possa sentir que o problema de quem ele ou ela constitui um problema particular, o africano sempre pergunta não 'quem sou eu?', mas ‘quem somos nós?'. 'Meu' problema não é apenas meu, mas 'nosso'. Essa constelação particular de problemas e projetos não é encontrada com freqüência fora da África: uma história colonial recente, uma multiplicidade de variadas tradições locais subnacionais, uma língua estrangeira cuja cultura metropolitana tradicionalmente definiu os 'nativos' como inferiores, por sua raça, e uma cultura literária ainda basicamente em processo de formação."

Sandra não possui muitos amigos brasileiros: "Eu só tenho uma amiga brasileira." Ela explica porque isso acontece:

"Às vezes eu penso que é mais o meu jeito de ser. Acho que tenho essa coisa assim: 'Ah, se eles são preconceituosos, então que cada um fique na sua.' Eu não vou forçar a barra, não vou implorar ninguém para fazer amizade. Eu vim inclusive aqui para ir embora. Eu não vou forçar nada, eu estou bem assim e é assim que eu vou ficar."

Há uma relação muito forte com os estudantes africanos, eles são extremamente ligados entre si, principalmente entre membros de seus próprios países, mas pôde ser percebido que há conflitos internos. Segundo Leandro:

"Mas a gente tem também conflito dentro de nós. Quando a gente olha outra comunidade a gente quer mostrar que a gente é unido. (...) Tem sempre um provérbio que a gente fala, que é : 'Guineense não se separa.' Se une, mas há conflitos. Mas tem sempre alguma coisa que atrai."

Há também uma certa diferenciação entre os africanos que vêm para Brasília e são mais pobres e aqueles mais ricos, como os filhos de diplomatas. Leandro explica: "Chega um negro africano, filho de diplomata, e de vez em quando nem quer se misturar com a gente. É certo. Se ele se misturar com a gente ele não vai ter alguns privilégios, sei lá.”

\footnotetext{
${ }^{9}$ Ver Kwame Anthony Appiah, op. cit., p. 115-116.
} 
Pôde ser percebido que no grupo investigado a discriminação brasileira é muito evidente, mas os aspectos xenófobos, que incluem a segregação, como a violência, não foram visualizados, pois no Brasil os danos do preconceito são muito mais relacionados aos escopos moral e emocional. Assim, a democracia racial brasileira colocada por Gilberto Freyre é desmistificada quando se passa a conviver com a sociedade brasileira e com o tipo de discriminação que existe no Brasil.

Alain Pascal descreve sua experiência de como é ser negro e africano no Brasil. O autor é de origem senegalesa e esteve no Brasil para completar seus estudos de pósgraduação. Com sua importante visão de africano no Brasil, ele explica:

"A grande maioria desses estudantes alega que um dos principais motivos da escolha do Brasil é a suposta democracia racial aqui existente. Os cientistas sociais que trabalham sobre as questões raciais no Brasil sustentam que a tese da democracia racial foi derrubada. Acontece fora do país, continua prevalecendo a existência da democracia racial. E o presidente da República* reiterou isso durante o seu discurso depois dos atentados do dia 11 de setembro nos Estados Unidos. 'O Brasil é um país de perfeito convívio racial e religioso', disse ele." ${ }^{10}$

Leandro diz que antes, em Guiné-Bissau, não tinha noção do que era o preconceito, apesar de haver uma hierarquia entre brancos negros interiorizada. Segundo ele, "A discriminação existe, mas não é consciente." E ele só percebeu como era realmente a discriminação no Brasil, onde ele teve contato de fato com as consequiências do preconceito, e sentiu como é ser excluído. Leandro disse: "Agora eu posso saber que as pessoas estão sendo discriminadas."

Oracy Nogueira compara o preconceito brasileiro, que é de marca, ou seja, por meio da cor da pele e por traços negróides, com o americano, que é de origem, o qual está ligado às origens étnicas da pessoa:

"Como observou certa vez Sérgio Milliet, enquanto nos Estados Unidos há uma linha de cor a separar os brancos de não-brancos, no Brasil há uma zona intermediária, fluida, vaga, até certo ponto, ao sabor do observador e das circunstâncias. Enquanto nos Estados Unidos exclui-se da categoria 'branco' todo indivíduo que se saiba ter ascendência não-branca, por mais remota e imperceptível que seja, no Brasil mesmo

\footnotetext{
${ }^{*} \mathrm{O}$ autor se refere ao Presidente Fernando Henrique Cardoso.

${ }^{10}$ Ver Alain Pascal Kaly, op. cit., p. 108 e nota de rodapé $n^{\circ} 3$.
} 
indivíduos com leves porém insofismáveis traços negróides são incorporados ao grupo branco, principalmente quando portadores de atributos que implicam status médio ou elevado (riqueza, diploma de curso superior e outros)."11

Sandra diz: "Eu percebi que tem preconceito, claro." Mas ela relata a curiosidade que as pessoas têm ao perceberem que ela é estrangeira: "Por ser africana o preconceito é menos, porque quando as pessoas descobrem que você é africana eles tipo pensam que é diferente, não é a mesma coisa. É uma viagem injusta, tratar uma pessoa de um jeito sabendo que ela não é daqui." Os brasileiros parecem que se interessam pelo que é diferente, apesar de em um primeiro momento haver o preconceito devido a cor da pele: " $O$ preconceito é pela cor da pele. Mas quando abro minha boca já começa a aproximar, e aí ficam curiosos. Aí que eu me fecho mesmo (.....”

Eduardo explica a causa de seu afastamento dos brasileiros, e assim a maior união entre os próprios africanos:

"Por que como é a amizade brasileira? Não todos, tem pessoas que são muito legais, mas tem outras que são assim, chegam perto por curiosidade, fazem muitas perguntas, matam a curiosidade e depois passam e nem te cumprimentam. Por isso que eu percebo o preconceito, por algumas perguntas tipo 'Ah, como você veio para cá, de barco?'. Eu não sei se é brincadeira ou se estão falando sério, mas eu por exemplo, evito essas coisas. Se a pessoa me fizer essa pergunta eu vou olhar dentro dos olhos dessa pessoa e não vou responder nada e sair da frente dela. Mas rola muito esses tipos de coisas. Talvez até por isso também, a gente se sente mais à vontade no meio dos africanos. (...) Você encontra mais raramente brasileiros que querem ser amigos de verdade, do que aqueles que querem ser simpáticos na hora e depois deixam para lá. Há pessoas que são simpáticas demais, e eu sou muito desconfiado, sempre fui. Aí do nada a pessoa some. Às vezes passa por você e nem te cumprimenta."

\section{Considerações Finais}

Há uma relação mais estreita dos estudantes entrevistados com os outros estudantes africanos, assim a amizade deles se concentra basicamente entre os africanos. Na verdade foi verificada uma escala hierárquica de relacionamentos, a qual é composta pelas relações entre os estudantes provenientes do mesmo país em primeiro lugar, seguida da amizade

\footnotetext{
${ }^{11}$ Ver Oracy Nogueira, op. cit., p. 6.
} 
entre os estudantes africano-lusófonos, pela amizade entre o grupo de todos os africanos de uma maneira geral, e em último lugar está a relação com os brasileiros.

Os estudantes provenientes do mesmo país mantêm relações mais estreitas por terem mais aspectos em comum e poderem conversar mais sobre a situações de seus países; os estudantes africano-lusófonos estão em segundo lugar devido ao fator da língua ser considerado um aspecto positivo, de maior entendimento entre eles; os outros estudantes, provenientes dos outros países africanos aparecem em seguida porque também são do continente africano e possuem um laço histórico parecido; foi verificado, entre o grupo pesquisado, que os brasileiros estão em último lugar nessa escala porque essa reação dos africanos, de afastamento e maior e integração entre o grupo africano, é reflexo de como os estudantes percebem o preconceito brasileiro e, até mesmo para evitá-lo, mantém uma relação de afastamento dos brasileiros.

Entre os estudantes entrevistados há conflitos internos, os quais estão relacionados a certas rivalidades entre os países e aos desejos que os estudantes têm de querer mostrar hábitos de seus próprios países, mesmo entre os próprios estudantes africanos.

Os angolanos são os estudantes que mantêm uma relação mais próxima entre si e, por virem angolanos com maior poder aquisitivo e que também mantêm maior relação com os filhos de diplomatas que residem em Brasília, eles acabam excluindo um pouco os outros estudantes africanos, principalmente aqueles de baixa renda. Assim, pôde ser percebido que esses conflitos, em último escopo, também é de ordem social.

A língua portuguesa não pode ser considerada fator de extrema união entre os países que a possuem como língua oficial. Na verdade, os estudantes entrevistados apresentaram grande dificuldade em falarem e serem compreendidos. Ou seja, apesar da língua ser um fator facilitador de comunicação, não é aspecto preponderante na interligação e maior unidade entre nações.

Nos países dos estudantes pesquisados, a imagem brasileira é basicamente construída pela mídia, deste modo os estudantes construíram uma imagem brasileira que distorce com a realidade que encontraram em Brasília. Pelas novelas, pelo futebol e pelo carnaval, eles viam harmonia, integração racial e miscigenação. Ao chegarem ao Brasil, conheceram uma realidade totalmente diferente, e isso os chocou um pouco. Convivendo com pessoas tidas como mais frias em Brasília e com um preconceito relacionado a cor e a 
traços negróides, esses estudantes desmistificaram a idéia de convivência pacífica que haveria entre as pessoas.

O preconceito brasileiro é ligado aos aspectos físicos em um primeiro momento, depois há a demonstração de curiosidade e exotismo ao saber que os estudantes pesquisados são africanos e, em seguida, a exclusão dos estudantes dos nacionais brasileiros faz com que esses estudantes que residem em Brasília se mantenham unidos entre si e evitem conviver tanto com os brasileiros.

O preconceito ligado a classe social também ficou evidenciado na medida em que os estudantes perceberam como os brasileiros tratam de maneira melhor aqueles estudantes que possuem maior poder aquisitivo. Isso pôde ser evidenciado no discurso do Carlos, estudante que diz nunca ter sofrido preconceito mas, na verdade, isso ocorreu devido ao fato dele ter grande poder aquisitivo e demonstrar isso externamente, como por exemplo, usando jóias e roupas de marcas tidas como famosas.

Os estudantes reconhecem o PEC-G como legítimo no Brasil e em seus países as pessoas também o reconhecem como tal, mas sabem das dificuldades que possui. A questão de o Brasil oferecer vagas nas universidades e não bolsas de estudos faz com que muitas famílias se sacrifiquem e os estudante às vezes passem necessidade por não ter dinheiro necessário para se manter no país.

\section{Referências Bibliográficas}

APPIAH, Kwame Anthony. Na Casa de Meu Pai: a África na Filosofia da Cultura. Rio de Janeiro: Contraponto, 1997.

PRITCHARD, Evans. E. Os Nuer: Uma descrição do modo de subsistência e das instituições políticas de um povo nilota. São Paulo: Editora Perspectiva, 2002.

FANON, Frantz. Os Condenados da Terra. Rio de Janeiro: Civilização Brasileira, 1968.

FREYRE, Gilberto. Casa Grande e Senzala. São Paulo: Global, 2003. 
O mundo que o português criou: aspectos das relações sociais e de cultura

do Brasil com Portugal e as colônias portuguesas. Rio de Janeiro: Livraria José Olympio Editora, 1940.

HOBSBAWM, Eric J. Nações e nacionalismos desde 1780: programa, mito e realidade. Rio de Janeiro: Paz e Terra, 1990.

KALY, Alain Pascal. O Ser Preto africano no "paraíso terrestre" brasileiro - Um sociólogo senegalês no Brasil. Lusotopie 2001: 105-121.

NOGUEIRA, ORACY. Tanto preto quanto branco: estudo de relações raciais. São Paulo: T.A. Queiroz, 1985. 